\title{
Analysis of intracorporeal knotting with invaginating suture versus endoloops in appendiceal stump closure
}

\author{
Mindaugas Kiudelis ${ }^{1}$, Povilas Ignatavicius ${ }^{1}$, Kristina Zviniene² ${ }^{2}$ Saulius Grizas ${ }^{1}$ \\ 1Department of Surgery, Lithuanian University of Health Sciences, Kaunas, Lithuania \\ 2Department of Radiology, Lithuanian University of Health Sciences, Kaunas, Lithuania
}

Videosurgery Miniinv 2013; 8 (1): 69-73

DOI: $10.5114 /$ wiitm.2011.31535

\begin{abstract}
Introduction: Laparoscopic appendectomy is a well-described surgical technique and has gained wide clinical acceptance. Laparoscopic appendectomy offers fewer wound infections, faster recovery and an earlier return to work in comparison to open surgery. However, concerns still exist regarding the appendiceal stump closure.

Aim: The aim of this study was to compare the overall incidence and specific intraoperative and postoperative complications after application of intracorporeal knotting with invaginating suture versus endoloops for stump closure in laparoscopic appendectomy.

Material and methods: One hundred fifty two consecutive patients according to the following inclusion criteria were included in the study: 1. Laparoscopic appendectomy was performed during the study period; 2. Acute phlegmonous or gangrenous appendicitis without perforation was diagnosed during operation. Exclusion criteria - patients with acute perforated appendicitis and local or diffuse peritonitis. Data was grouped according to the appendiceal stump closure technique, with either endoloops - 112 patients (73.7 percent) or intracorporeal knotting with invaginating suture -40 patients (26.3 per cent). The primary outcome measure was the rate of intraabdominal surgical-site infection, defined as post-operative intra-abdominal abscess. Secondary outcome variables were intraoperative and postoperative complications, duration of operation, hospital stay.

Results: There were no significant differences between the two groups in overall intraoperative and postoperative complications rate and in hospital stay. The median duration of operation was significantly shorter when the endoloop was used. The use of intracorporeal knotting with invaginating suture instead of endoloop to close the appendiceal stump decreased the total cost of laparoscopic appendectomy.

Conclusions: According our study results, intracorporeal knotting with invaginating suture appendiceal stump closure technique is acceptable laparoscopic procedure, which intraoperative and postoperative results do not differ from endoloops technique. The total cost of this procedure is $80 €$ cheaper then endoloops technique.
\end{abstract}

Key words: laparoscopic appendectomy, appendiceal stump closure, endoloop, invaginating suture.

\section{Introduction}

Laparoscopic appendectomy is a well-described surgical technique and has gained wide clinical acceptance. Laparoscopic appendectomy offers fewer wound infections, faster recovery and an earlier return to work in comparison to open surgery [1-7]. However, concerns still exist regarding appendiceal stump closure [8-10]. Closure of the appendiceal stump is an important step because of postoperative 
complications from its inappropriate management. The development of life-threatening events such as stercoral fistulas, postoperative peritonitis, and sepsis is feared and unwanted. The tactical modification of appendiceal stump closure with a single endoligature, replacing the invaginating suture, adjusted very well to laparoscopic appendectomy, and nowadays is the procedure of choice, whenever possible. Among the alternatives that do not make use of an invaginating suture, studies advocate the use of an endostapler, endoligature (endoloop), metal clips, bipolar endocoagulation, and polymeric clips [11-16]. An advantage of endoloops is that they are 6 to 12 times cheaper than stapling devices, but invaginating intracorporeal suture is even cheaper than endoloops.

\section{Aim}

The aim of this study was to compare the overall incidence and specific intraoperative and postoperative complications after application of intracorporeal knotting with invaginating suture versus endoloops for stump closure in laparoscopic appendectomy.

\section{Material and methods}

\section{Study design and patient population}

This was a prospective, non-randomized study, in which 152 patients with acute uncomplicated appendicitis were studied. Patients were treated at the Department of Surgery from January 2004 to Decem- ber 2009. All patients provided written informed consent and the Local Ethical Committee approved the study (no. BE-1-24). One hundred fifty-two consecutive patients according to the following inclusion criteria were included in the study: (1) laparoscopic appendectomy was performed during the study period; (2) acute phlegmonous or gangrenous appendicitis without perforation was diagnosed during operation. Patients with acute perforated appendicitis and local or diffuse peritonitis were excluded from the study. Diagnosis of acute appendicitis was based on disease history and clinical symptoms, and laboratory tests (elevated leukocyte count, elevated C-reactive protein). The preoperative diagnosis of acute appendicitis was confirmed by ultrasound. Laparoscopic appendectomies were performed by experienced surgeons. Data were grouped according to the appendiceal stump closure technique, with either endoloops (PDS-Endoloop ${ }^{\circledR}$ 2-0; Ethicon, Johnson \& Johnson Medical) (112 patients; 73.7\%) or intracorporeal knotting with invaginating suture (polyglactin) (40 patients; $26.3 \%$ ). The stump closure technique was chosen by the operating surgeon. Patients' data are summarized in Table I. The primary outcome measure was the rate of intraabdominal surgical-site infection, defined as postoperative intra-abdominal abscess. Secondary outcome variables were intraoperative and postoperative complications, duration of operation, total operation cost and hospital stay. Postoperative complications included superficial sur-

Table I. Demographic data

\begin{tabular}{|lccc|}
\hline Parameter & Invaginating suture $(n=40)$ & Endoloop $(n=112)$ & Value of $p$ \\
\hline Age [years] & $32.1 \pm 13.1$ & $32.4 \pm 12.3$ & NS \\
\hline \begin{tabular}{l} 
Gender: \\
\hline Male
\end{tabular} & $15(37.5 \%)$ & $62(55 \%)$ & NS \\
\hline Female & $25(62.5 \%)$ & $50(45 \%)$ & NS \\
\hline BMI $\left[\mathrm{kg} / \mathrm{m}^{2}\right]$ & $24.3 \pm 4.0$ & $25.2 \pm 4.8$ & NS \\
\hline Duration of illness $[\mathrm{h}]$ & $27.6 \pm 29.6$ & $25.5 \pm 18.7$ & NS \\
\hline ASA grade: & $10(25 \%)$ & & NS \\
\hline I & $22(55 \%)$ & $31(28 \%)$ & NS \\
\hline II & $8(20 \%)$ & $54(48 \%)$ & NS \\
\hline III & $27(24 \%)$ & \\
\hline
\end{tabular}

$B M I$ - body mass index, ASA - American Society of Anesthesiologists, NS - not statistically significant 
gical-site infection, and access-related complications, such as lesions caused by a Veress needle or by limited open access.

\section{Surgical technique}

The laparoscopic approach was standardized with the use of a 10-mm infraumbilical optic trocar, a 5-mm trocar in the lower left abdomen, and a 10-mm trocar in the lower right abdomen. The mesoappendix was dissected using bipolar coagulation. We placed one endoloop or polyglactin ligature with intracorporeal knotting to the appendix base. An additional loop or the second polyglactin ligature was placed $10 \mathrm{~mm}$ distally. The base was cut with laparoscopic scissors between the loops or ligatures. When polyglactin ligature with intracorporeal knotting was used, additionally invaginating suture was placed on the cecum in order to sink the stump. We used a tube or an endobag to evacuate the appendix through the trocar in the right abdomen.

All patients received intravenous $240 \mathrm{mg}$ gentamicin and $500 \mathrm{mg}$ metronidazole preoperatively.

\section{Statistical analysis}

The data are presented as mean \pm standard deviation or median and range. Fisher's exact test was used to analyze intergroup differences for proportional data. The patients' age, body mass index (BMI), duration of illness, hospital stay and duration of operation between the groups were compared using the unpaired Mann-Whitney $U$ test. Value of $p<0.05$ was considered significant.

\section{Results}

There were no significant differences between the two groups in the overall intraoperative and postoperative complication rate or in hospital stay (Table II). The median duration of the operation was significantly shorter when the endoloop was used. The total cost of laparoscopic appendectomy with endoloop was $€ 460$. The use of intracorporeal knotting with invaginating suture instead of endoloop to close the appendiceal stump decreased the total cost of laparoscopic appendectomy by up to $€ 380$.

\section{Discussion}

Because of faster postoperative recovery and reduced postoperative complications, laparoscopic appendectomy is more and more widely used for treating acute appendicitis [3-5, 17-19]. Studies show various results, from no difference in the rate of postoperative intra-abdominal abscess between laparoscopic and open appendectomy to an increase in the incidence of intra-abdominal abscess after laparoscopic appendectomy [3-6, 20, 21].

The key technical aspect in laparoscopic appendectomy is the treatment of appendiceal stump closure. Nowadays, stapling and endoloop techniques are the most popular ones in securing the appendiceal stump. Some randomized and prospective clinical trials $[1,14,16]$ have compared staplers and endoloops for appendiceal stump closure but did not find any significant difference in the incidence of intra-abdominal abscesses. The authors noted that

Table II. Intraoperative and postoperative complications

\begin{tabular}{|lccc|}
\hline Parameter & Invaginating suture $(n=40)$ & Endoloop $(n=112)$ & Value of $p$ \\
\hline Duration of surgery [min] & $79.6 \pm 21.1$ & $58.4 \pm 14.3$ & $>0.05$ \\
\hline Intra-abdominal surgical-site infection & $2(5 \%)$ & $4(3.6 \%)$ & NS \\
\hline Superficial surgical-site infection & 0 & $3(2.7 \%)$ & NS \\
\hline Intraoperative complications: & $1(2.5 \%)$ & $2(1.8 \%)$ & NS \\
\hline Bleeding & 0 & $1(0.9 \%)$ & NS \\
\hline Organ lesion & 0 & $1(0.9 \%)$ & NS \\
\hline Access related & $2.8 \pm 2.2$ & $2.4 \pm 1.2$ & NS \\
\hline Hospital stay [days]
\end{tabular}

NS - not statistically significant 
appendiceal stump closure using an endoloop is an easy, safe, and cost-effective procedure.

On the other hand, Beldi et al. [11] in their nonconcurrent cohort study found that among 4489 patients with acute appendicitis there was a significantly higher rate of intra-abdominal surgical-site infection and readmission to hospital in the endoloop group, compared with stapling. The meta-analysis of Kazemier et al. [13] of 427 patients in four randomized controlled trials on appendix stump closure favored the routine use of endoscopic staplers. Superficial wound infections and postoperative ileus were obviously less frequent when the appendix stump was secured with staplers, but there was no significant difference with respect to intra-abdominal abscess.

Securing the appendiceal stump with endoloops involves the application of one or two proximal ligatures and one distal ligature around the base of the appendix, which results in extraversion of the appendiceal stump mucosa, as opposed to the inversion of the mucosa with stapling devices [12]. The higher rate of abscess formation after endoloop closure might be explained by insufficient closure of the stump or exposure of the remaining contaminated mucosa to the abdominal cavity. Mucosal necrosis with loosening of the ligature could be postulated as another mechanism of leakage [11].

In our study, in order to avoid the aforementioned potential risk factors, after placing the ligature at the appendix base and cutting it, we sank the stump with the help of invaginating suture. Although we did not find any significant differences between endoloops and intracorporeal knotting with invaginating suture in the overall intraoperative and postoperative complication rate, the duration of the operation was significantly longer when invaginating suture was used.

The weakness of our study is that it is a prospective one but not a randomized clinical trial. Considering the nature of this study, patients were not randomized, but distributed to one of the groups (endoloops or intracorporeal knotting with invaginating suture) according to the operating surgeon's chosen appendiceal stump closure technique. Considering this, the cohort of these two groups was not equal and homogeneous: more experienced surgeons chose the intracorporeal knotting with invaginating suture technique, because it requires considerable expertise in laparoscopic suturing techniques.
Younger and less experienced surgeons chose the endoloop technique. We can only speculate that with an equal and greater number of patients in both groups, there could be a significant difference in the overall intraoperative and postoperative complication rate when comparing these two surgical techniques.

The most important factor in deciding which technique to use in routine clinical practice is the cost-benefit analysis. Even today, the decision of choosing the appendiceal stump closure technique in laparoscopic surgery is based on the preference of the surgeon and the institution. The Lithuanian health insurance system does not cover the material costs of stapler use in laparoscopic appendectomy. Our institution's selective concept includes as a standard procedure appendiceal stump closure by endoloops. Our study results demonstrated that intracorporeal knotting with invaginating suture appendiceal stump closure technique is the cheaper one, because the total cost of laparoscopic appendectomy decreased from $€ 460$ to $€ 380$.

\section{Conclusions}

According to our study results, intracorporeal knotting with invaginating suture appendiceal stump closure technique is an acceptable laparoscopic procedure, whose intraoperative and postoperative results do not differ from the endoloop technique. The total cost of this procedure is $€ 80$ cheaper than the endoloop technique.

\section{References}

1. Ortega AE, Hunter JG, Peters JH, et al. A prospective, randomized comparison of laparoscopic appendectomy with open appendectomy. Laparoscopic Appendectomy Study Group. Am J Surg 1995; 169: 208-12.

2. Tuggle KR, Ortega G, Bolorunduro OB, et al. Laparoscopic versus open appendectomy in complicated appendicitis: a review of the NSQIP database. J Surg Res 2010; 163: 225-8.

3. Bennett J, Boddy A, Rhodes M. Choice of approach for appendicectomy: a meta-analysis of open versus laparoscopic appendicectomy. Surg Laparosc Endosc Percutan Tech 2007; 17: 245-55.

4. Liu Z, Zhang P, Ma Y, et al. Laparoscopy or not: a meta-analysis of the surgical effects of laparoscopic versus open appendicectomy. Surg Laparosc Endosc Percutan Tech 2010; 20: 362-70.

5. Guller U, Hervey S, Purves $H$, et al. Laparoscopic versus open appendectomy: outcomes comparison based on a large administrative database. Ann Surg 2004; 239: 43-52.

6. Kapischke M, Caliebe A, Tepel J, et al. Open versus laparoscopic appendicectomy: a critical review. Surg Endosc 2006; 20: 1060-8. 
7. Kwiatkowski A, Pasnik K, Trojanowski P. Late caecal fistula after laparoscopic appendectomy managed mini-invasively - case report. Videosurgery Miniinv 2011; 6: 246-8.

8. Gomes CA, Nunes TA, Soares C Jr, et al. The appendiceal stump closure during laparoscopy: historical, surgical, and future perspectives. Surg Laparosc Endosc Percutan Tech 2012; 22: 1-4.

9. Gonenc M, Gemici E, Kalayci MU, et al. Intracorporeal knotting versus metal endoclip application for the closure of the appendiceal stump during laparoscopic appendectomy in uncomplicated appendicitis. J Laparoendosc Adv Surg Tech A 2012; 22: 231-5.

10. Alis $\mathrm{H}$, Gonenc M, Deniztas C, et al. Metal endoclips for the closure of the appendiceal stump in laparoscopic appendectomy. Tech Coloproctol 2012; 16: 139-41.

11. Beldi G, Vorburger SA, Bruegger LE, et al. Analysis of stapling versus endoloops in appendiceal stump closure. Br J Surg 2006; 93: 1390-3.

12. Beldi G, Muggli K, Helbling C, et al. Laparoscopic appendectomy using endoloops: a prospective, randomized clinical trial. Surg Endosc 2004; 18: 749-50.

13. Kazemier G, In't Hof KH, Saad S, et al. Securing the appendiceal stump in laparoscopic appendectomy: evidence for routine stapling? Surg Endosc 2006; 20: 1473-6.

14. Klima S. Importance of appendix stump management in laparoscopic appendectomy. Zentralbl Chir 1998; 123 Suppl 4: 90-3.

15. Hanssen A, Plotnikov S, Dubois R. Laparoscopic appendectomy using a polymeric clip to close the appendicular stump. JSLS 2007; 11: 59-62.

16. Sahm M, Kube R, Schmidt S, et al. Current analysis of endoloops in appendiceal stump closure. Surg Endosc 2011; 25: 124-9.

17. Kazemier G, In't Hof KH, Saad S, et al. Securing the appendiceal stump in laparoscopic appendectomy: evidence for routine stapling? Surg Endosc 2006; 20: 1473-6.

18. Duda M, Ryga A, Zudek S, et al. Twenty years of minimally invasive surgery in the Czech Republic. Videosurgery Miniinv 2011; 6: $42-7$.

19. Rembiasz K, Bobrzyński A, Budzyński A, et al. Analysis of complications of laparoscopic management of abdominal diseases related to extended indications. Videosurgery Miniinv 2010; 5: 53-9.

20. Wilms IM, de Hoog DE, de Visser DC, et al. Appendectomy versus antibiotic treatment for acute appendicitis. Cochrane Database Syst Rev 2011; 11: CD008359.

21. Varadhan KK, Neal KR, Lobo DN. Safety and efficacy of antibiotics compared with appendicectomy for treatment of uncomplicated acute appendicitis: meta-analysis of randomised controlled trials. BMJ 2012; 344: e2156.

Received: 21.08.2012, revised: 8.09.2012, accepted: 24.09.2012. 